\title{
A four-step reduced mechanism for syngas combustion
}

\author{
P. Boivin ${ }^{\mathrm{a}}$, C. Jiménez ${ }^{\mathrm{a}, \mathrm{b}}$, A. L. Sánchez ${ }^{\mathrm{a}}$, F.A. Williams ${ }^{\mathrm{c}}$ \\ ${ }^{a}$ Dept. Ingeniería Térmica y de Fluidos, Universidad Carlos III de Madrid, Leganés \\ 28911, Spain \\ ${ }^{b}$ Dept. Combustibles Fósiles, Centro de Investigaciones Energéticas, Medioambientales y \\ Tecnológicas, Madrid, Spain \\ ${ }^{c}$ Dept. of Mechanical and Aerospace Engineering, University of California San Diego, La \\ Jolla CA 92093-0411, USA
}

\begin{abstract}
A four-step reduced chemical-kinetic mechanism for syngas combustion is proposed for use under conditions of interest for gas-turbine operation. The mechanism builds upon our recently published three-step mechanism for $\mathrm{H}_{2}-$ air combustion (Boivin et al., Proc. Comb. Inst. 33, 2010), which was derived from a 12-step skeletal mechanism by assuming $\mathrm{O}, \mathrm{OH}$, and $\mathrm{H}_{2} \mathrm{O}_{2}$ to be in chemical-kinetic steady state and includes a correction to account for the failure of the $\mathrm{O}$ and $\mathrm{OH}$ steady states during autoignition. The analysis begins by appropriately extending the number of elementary steps in the skeletal description to enable computation of the CO chemistry for mixtures with appreciable $\mathrm{H}_{2}$ content, giving a total of 16 elementary steps. It is seen that the formyl radical HCO, which appears as the only additional relevant intermediate in the extended chemical description, follows accurately a steady-state approximation, which can be used along with the steady-state approximations for $\mathrm{O}, \mathrm{OH}$, and $\mathrm{H}_{2} \mathrm{O}_{2}$ to derive the reduced description, involving the three global steps of our previous $\mathrm{H}_{2}$-air mechanism, $3 \mathrm{H}_{2}+\mathrm{O}_{2} \rightleftharpoons$ $2 \mathrm{H}_{2} \mathrm{O}+2 \mathrm{H}, 2 \mathrm{H}+\mathrm{M} \rightleftharpoons \mathrm{H}_{2}+\mathrm{M}$, and $\mathrm{H}_{2}+\mathrm{O}_{2} \rightleftharpoons \mathrm{HO}_{2}+\mathrm{H}$, along with the additional step $\mathrm{CO}+\mathrm{H}_{2} \mathrm{O} \rightleftharpoons \mathrm{CO}_{2}+\mathrm{H}_{2}$. Expressions are given for the rates
\end{abstract}


of the four global reactions in terms of those of the elementary steps of the skeletal mechanism, with concentrations of the different steady-state species also given in explicit form. Comparisons of results of computations of laminar burning velocities and induction times with published experimental data for $\mathrm{H}_{2} / \mathrm{CO} / \mathrm{O}_{2}$ mixtures with different diluents at atmospheric and elevated pressures and for varying equivalence ratios and initial temperatures indicate that the reduced description can be applied with reasonable accuracy in numerical studies of gas-turbine syngas combustion.

Key words: syngas, reduced chemistry, burning rate, induction times, gas-turbine combustion

\section{Introduction}

The development of IGCC technologies, involving gas-turbine combustion of the syngas derived by air or $\mathrm{O}_{2}$ gasification of pulverized coal, has recently promoted interest in studies of $\mathrm{CO} / \mathrm{H}_{2}$ combustion. Several detailed mechanisms are now available for accurate description of the combustion process under conditions of practical interest [1, 2, 3], although chemical-kinetic uncertainties still exist for low-temperature autoignition processes at elevated pressure [4] and also for laminar flame propagation at high-pressure fuel-rich conditions and in strongly preheated mixtures [5]. Because of the relatively large number of chemical species and elementary rates appearing in these detailed mechanisms, their use in computations of high-Reynolds-number flows in complex geometries is still prohibitively expensive for most purposes, given the present computational capabilities. Reduced mechanisms, systematically derived from detailed chemical schemes by introduction of steady states for intermediate species, represent an attractive alternative to shorten computational times, while providing sufficient accuracy to yield reliable computa- 
tional results.

Regardless of the coal type and gasification technology, the syngas mixture always contains significant amounts of $\mathrm{CO}$ and $\mathrm{H}_{2}$ as the main reactive species along with diluents such as $\mathrm{N}_{2}, \mathrm{CO}_{2}$ and $\mathrm{H}_{2} \mathrm{O}$, while the hydrocarbon content, mainly $\mathrm{CH}_{4}$, is in general very limited, especially when $\mathrm{O}_{2}$-enriched gasification is employed. In deriving chemistry descriptions for syngas combustion, it therefore appears reasonable to focus on the chemistry of CO and $\mathrm{H}_{2}$, neglecting the contribution of the hydrocarbon chemistry to the overall combustion process. Since the $\mathrm{H}_{2} / \mathrm{CO}$ volume ratio in most syngas mixtures typically exceeds 0.25 and often takes on values that are of the order of 0.5 or above, it is found that the hydrogen chemistry plays a dominant role in syngas combustion. A result is that most syngas mixtures exhibit large burning rates and small autoignition times, comparable to those found in hydrogen combustion.

\section{The reduced chemistry}

The CO- $\mathrm{H}_{2}$ submechanism of the so-called San Diego mechanism [2], comprising 30 elementary reactions among 11 reactive chemical species (CO, $\mathrm{CO}_{2}, \mathrm{HCO}, \mathrm{O}_{2}, \mathrm{H}_{2}, \mathrm{H}_{2} \mathrm{O}, \mathrm{H}_{2} \mathrm{O}_{2}, \mathrm{O}, \mathrm{H}, \mathrm{OH}$ and $\mathrm{HO}_{2}$ ), will be used as a detailed-chemistry description for validation purposes.

Of the 21 steps in this mechanism that do not involve carbon atoms, a subset of twelve elementary steps, numbered 1-12 in Table 1, with the subscript $f$ and $b$ employed to denote forward and backward reactions, recently has been found [6] to give sufficiently accurate predictions for laminar burning velocities and induction times of $\mathrm{H}_{2}$-air mixtures, as well as for structures and propagation velocities of detonations and strain-rate dependences of properties of $\mathrm{H}_{2}$-air nonpremixed flames. Although not all of these elementary steps are essential for gas-turbine combustion (e.g., $8 b$ and $9 b$ need to be retained 
only if high-temperature equilibrium is to be described accurately, as occurs in detonations), no significant simplification follows from discarding any one of the less important rates, so that the following development employs all twelve reactions, as they appear in the table, for describing $\mathrm{H}_{2}$ oxidation in syngas combustion.

Starting with a mechanism comprising reactions 1-12 augmented with the three reactions for $\mathrm{CO}$ conversion to $\mathrm{CO}_{2}$ and the six $\mathrm{HCO}$ reactions of the San Diego mechanism [2], extensive computations of premixed flames and homogeneous ignition histories were performed to elucidate the minimum number of additional species and elementary steps needed to describe also the COoxidation chemistry of $\mathrm{CO} / \mathrm{H}_{2}$ mixtures containing $\mathrm{H}_{2}$ in relative amounts typical of syngas, i.e., mole-fraction ratios $0.10 \lesssim X_{\mathrm{H}_{2}} /\left(X_{\mathrm{CO}}+X_{\mathrm{H}_{2}}\right) \lesssim 0.60$. It was found that adding only four elementary steps, numbered 13-16 in Table 1 , with only 13 and 15 being reversible, sufficed to provide reasonably accurate predictions of burning rates and induction times under conditions of interest for gas-turbine combustion. Along with reaction 13, which is known to be central to $\mathrm{CO}$ oxidation, the extended mechanism includes reactions 15 and $16 f$, because they are needed for describing stoichiometric and rich flames, with deletion of $15 b$ leading in particular to large overpredictions of burning rates for rich mixtures. On the other hand, reaction 14f, unimportant for flame propagation, was found to be essential for describing autoignition for conditions near the second explosion limit, in agreement with previous studies [7]. For the conditions tested herein, all additional reactions of the San Diego mechanism [2], including $\mathrm{CO}+\mathrm{O}_{2} \rightleftharpoons \mathrm{CO}_{2}+\mathrm{O}$ as well as formyl reactions with $\mathrm{O}, \mathrm{OH}$, and $\mathrm{O}_{2}$, were found to have a negligible effect on the combustion process. The overall skeletal mechanism therefore consists of 16 reactions, 8 reversible, and 11 reactive species. 
The reduction continues by introducing steady-state assumptions for intermediates, as is appropriate for $\mathrm{O}, \mathrm{OH}$ and $\mathrm{H}_{2} \mathrm{O}_{2}$ in hydrogen-air deflagrations [6], as well as in $\mathrm{CO} / \mathrm{H}_{2}$-air deflagrations, as indicated by our computations, with $\mathrm{HCO}$ also accurately obeying a steady state in the latter system. With these approximations, the chemistry for $\mathrm{CO} / \mathrm{H}_{2}$ oxidation reduces to the four global steps

$$
\begin{array}{rll}
3 \mathrm{H}_{2}+\mathrm{O}_{2} & \stackrel{\mathrm{I}}{\rightleftharpoons} & 2 \mathrm{H}_{2} \mathrm{O}+2 \mathrm{H} \\
2 \mathrm{H}+\mathrm{M} & \stackrel{\mathrm{II}}{\rightleftharpoons} & \mathrm{H}_{2}+\mathrm{M} \\
\mathrm{H}_{2}+\mathrm{O}_{2} & \stackrel{\text { III }}{\rightleftharpoons} & \mathrm{HO}_{2}+\mathrm{H} \\
\mathrm{CO}+\mathrm{H}_{2} \mathrm{O} & \stackrel{\mathrm{IV}}{\rightleftharpoons} & \mathrm{CO}_{2}+\mathrm{H}_{2}
\end{array}
$$

with rates given in terms of the different elementary reaction rates by the expressions

$$
\begin{aligned}
\omega_{\mathrm{I}} & =\omega_{1}+\omega_{5 f}+\omega_{10 f}+\omega_{11 f}+\omega_{14 f}, \\
\omega_{\mathrm{II}} & =\omega_{4 f}+\omega_{8}+\omega_{9}-\omega_{10 f}-\omega_{11 f}-\omega_{15}, \\
\omega_{\mathrm{III}} & =\omega_{4 f}-\omega_{5 f}-\omega_{6}-\omega_{7 f}-2 \omega_{10 f}-\omega_{11 f}-\omega_{14 f}, \\
\omega_{\mathrm{IV}} & =\omega_{13}+\omega_{14 f} .
\end{aligned}
$$

The temperature $T$ and the concentrations $C_{i}$ of the seven species of the reduced mechanism $\left(\mathrm{O}_{2}, \mathrm{H}_{2}, \mathrm{CO}, \mathrm{H}_{2} \mathrm{O}, \mathrm{CO}_{2}, \mathrm{H}, \mathrm{H}_{2} \mathrm{O}\right)$ enter in the computation of the above elementary rates. The computation of $\omega_{1 b}, \omega_{7 f}, \omega_{8 f}$, and $\omega_{13 f}$ requires also knowledge of the $\mathrm{OH}$ concentration $C_{\mathrm{OH}}$, while the O-atom and formyl concentrations $C_{\mathrm{O}}$ and $C_{\mathrm{HCO}}$ are needed to compute $\omega_{1 b}$ and $\omega_{15 f}$, respectively. These additional concentrations can be obtained by solving the four steady-state equations derived by equating the production 
and consumption chemical rates of $\mathrm{OH}, \mathrm{O}, \mathrm{H}_{2} \mathrm{O}_{2}$, and $\mathrm{HCO}$ given by the skeletal mechanism, yielding the explicit expressions

$$
\begin{aligned}
C_{\mathrm{OH}} & =\left[\left(A_{1}^{2}+4 A_{0} A_{2}\right)^{1 / 2}-A_{1}\right] /\left(2 A_{2}\right), \\
C_{\mathrm{O}} & =\frac{k_{1 f} C_{\mathrm{H}} C_{\mathrm{O}_{2}}+k_{2 b} C_{\mathrm{OH}} C_{\mathrm{H}}}{k_{1 b} C_{\mathrm{OH}}+k_{2 f} C_{\mathrm{H}_{2}}}, \\
C_{\mathrm{HCO}} & =\frac{k_{15 b} C_{\mathrm{CO}} C_{\mathrm{H}} C_{\mathrm{M}}}{k_{15 f} C_{\mathrm{M}}+k_{16 f} C_{\mathrm{H}}},
\end{aligned}
$$

with

$$
\begin{aligned}
A_{0}= & k_{2 f} C_{\mathrm{H}_{2}}\left(2 k_{1 f} C_{\mathrm{H}} C_{\mathrm{O}_{2}}+k_{3 b} C_{\mathrm{H}} C_{\mathrm{H}_{2} \mathrm{O}}+2 k_{5 f} C_{\mathrm{H}} C_{\mathrm{HO}_{2}}+k_{8 b} C_{\mathrm{M}} C_{\mathrm{H}_{2} \mathrm{O}}\right. \\
& \left.+2 k_{10 f} C_{\mathrm{HO}_{2}}^{2}+2 k_{11 f} C_{\mathrm{HO}_{2}} C_{\mathrm{H}_{2}}+k_{13 b} C_{\mathrm{CO}_{2}} C_{\mathrm{H}}+k_{14 f} C_{\mathrm{CO}} C_{\mathrm{HO}_{2}}\right), \\
A_{1}= & k_{2 f} C_{\mathrm{H}_{2}}\left(k_{3 f} C_{\mathrm{H}_{2}}+k_{7 f} C_{\mathrm{HO}_{2}}+k_{8 f} C_{\mathrm{M}} C_{\mathrm{H}}+k_{13 f} C_{\mathrm{CO}}\right) \\
& -k_{1 b}\left(k_{3 b} C_{\mathrm{H}} C_{\mathrm{H}_{2} \mathrm{O}}+2 k_{5 f} C_{\mathrm{H}} C_{\mathrm{HO}_{2}}+k_{8 b} C_{\mathrm{M}} C_{\mathrm{H}_{2} \mathrm{O}}\right. \\
& \left.+2 k_{10 f} C_{\mathrm{HO}_{2}}^{2}+2 k_{11 f} C_{\mathrm{HO}_{2}} C_{\mathrm{H}_{2}}+k_{13 b} C_{\mathrm{CO}_{2}} C_{\mathrm{H}}+k_{14 f} C_{\mathrm{CO}} C_{\mathrm{HO}_{2}}\right), \\
A_{2}= & k_{1 b}\left(2 k_{2 b} C_{\mathrm{H}}+k_{3 f} C_{\mathrm{H}_{2}}+k_{7 f} C_{\mathrm{HO}_{2}}+k_{8 f} C_{\mathrm{M}} C_{\mathrm{H}}+k_{13 f} C_{\mathrm{CO}}\right) .
\end{aligned}
$$

As discussed in [6], the steady states for $\mathrm{O}$ and $\mathrm{OH}$, which hold with reasonable accuracy in flames, fail however during autoignition events, thereby leading to significant underpredictions of induction times, with errors increasing for decreasing equivalence ratio. An appropriate correction to the branching rate, developed [6] from an analytical determination of the autoignition eigenvalue under lean conditions, is obtained by introducing, during the chain-branching period that leads to autoignition, modified rates $\omega_{\mathrm{I}}^{*} / \omega_{\mathrm{I}}=\omega_{\mathrm{II}}^{*} / \omega_{\mathrm{II}}=\omega_{\mathrm{III}}^{*} / \omega_{\mathrm{III}}=\omega_{\mathrm{IV}}^{*} / \omega_{\mathrm{IV}}=\Lambda$, where the factor

$$
\Lambda=\left[(1+2 B)^{1 / 2}-1\right] / B
$$

depends on the forward rates of the shuffle reactions 1-3 through

$$
B=\frac{4 k_{1 f} C_{\mathrm{O}_{2}}\left(k_{1 f} C_{\mathrm{O}_{2}}+k_{2 f} C_{\mathrm{H}_{2}}+k_{3 f} C_{\mathrm{H}_{2}}\right)}{k_{2 f} k_{3 f} C_{\mathrm{H}_{2}}^{2}} .
$$

The modification must be switched off by setting $\Lambda=1$ in places where the steady states for $\mathrm{O}$ and $\mathrm{OH}$ apply, which occur in general in hot regions with 
relatively high radical concentrations, where the $\mathrm{HO}_{2}$ steady state also holds. Therefore, one may link the need for the correction factor to the failure of the $\mathrm{HO}_{2}$ steady state. To that end, in computations with the reduced chemistry, the rate of $\mathrm{HO}_{2}$ production $\dot{C}_{\mathrm{HO}_{2 P}}=\omega_{4 f}+\omega_{6 b}$ and that of $\mathrm{HO}_{2}$ consumption $\dot{C}_{\mathrm{HO}_{2 C}}=\omega_{5 f}+\omega_{6 f}+\omega_{7 f}+2 \omega_{10 f}+\omega_{11 f}+\omega_{14 f}$ must be evaluated locally. The steady state is regarded as a valid approximation wherever $\mid \dot{C}_{\mathrm{HO}_{2 P}}-$ $\dot{C}_{\mathrm{HO}_{2 C}} \mid / \dot{C}_{\mathrm{HO}_{2 P}}$ is smaller than a presumed small threshold value, below which $\Lambda=1$, whereas for larger values (5) must be used, since autoignition may be occurring. The numerical results were checked to be independent of the threshold value selected, provided it is sufficiently small, with the switch-off criterion $\left|\dot{C}_{\mathrm{HO}_{2 P}}-\dot{C}_{\mathrm{HO}_{2 C}}\right| / \dot{C}_{\mathrm{HO}_{2 P}}<0.05$, employed in [6], also being used below for computational purposes. Note that, since the first twelve steps of the skeletal mechanism in Table 1 are identical to those used in [6], in the absence of $\mathrm{CO}$ the four-step mechanism described above naturally reduces to the three-step mechanism given in [6] for $\mathrm{H}_{2}$-air combustion.

\section{Validation of the reduced mechanism}

To test the degree of accuracy associated with the chemical simplifications, laminar flame velocities and induction times determined numerically with the reduced mechanism were compared with those obtained from both detailed-chemistry computations and computations with the skeletal mechanism of Table 1. All computations were performed with the COSILAB code [8] with radiation transport neglected and with a multicomponent transport description including thermal diffusion. In addition, to test practical applicability, the results were compared with recent experimental data. In particular, Figs. 13 test the predictive capability of the chemical-kinetic mechanisms with regard to burning rates, whereas Fig. 4 is used to compare predictions of ignition times. 
Different pressures are considered in Fig. [1 for two different values of the $\mathrm{CO} / \mathrm{H}_{2}$ ratio characteristic of typical syngas mixtures. The performance of the reduced mechanism is seen to be satisfactory for all conditions investigated, based on comparisons with both the detailed and skeletal mechanisms. For very rich mixtures at the highest pressure shown, the detailed-chemistry description employed here consistently gives burning rates that are much larger than those obtained in experiments, while there are other descriptions that produce better agreement [3]. The detailed chemistry deserves further attention for these conditions. For all other conditions, the agreement of the detailed and skeletal mechanisms with the experiments is very good, while the reduced mechanism tends to overpredict burning rates as a result of the steady-state assumptions introduced, with errors being typically smaller than $15 \%$.

Preheat is investigated in Fig. 2, along with fuel dilution with $\mathrm{CO}_{2}$. Both effects are well reproduced by the reduced chemistry, except in highly preheated mixtures, with $T_{u}=700 \mathrm{~K}$, where overpredictions of flame velocities, in comparison with predictions of the detailed chemistry are on the order of $15 \%$. With strong preheat, besides significant errors associated with the steady-state simplifications, there exist noticeable discrepancies between the detailed-chemistry predictions and the experimental results [11], further augmenting reduced-chemistry discrepancies and calling for future detailedchemistry investigation, even though experimentally it might be difficult to suppress pre-reaction at such high initial temperatures.

The dependence of the burning rate on the relative $\mathrm{CO} / \mathrm{H}_{2}$ content of the fuel mixture is shown in Fig. 3 at both atmospheric and elevated pressure and for conditions ranging from pure $\mathrm{H}_{2}$ to pure $\mathrm{CO}$ and including preheated mixtures and fuel dilution with $\mathrm{CO}_{2}$. It can be seen that both the detailed 
and the skeletal mechanisms agree well with the experimental measurements for all of these conditions, whereas the reduced mechanism tends to overpredict burning rates. As in Fig. 1, errors are seen to be typically smaller than $15 \%$, the only exception being fuel mixtures with very small $\mathrm{H}_{2}$ content, for which the errors become larger, especially for atmospheric combustion.

Autoignition times, defined by a temperature-inflexion criterion for homogeneous adiabatic ignition computations in an isobaric reactor, are compared in Fig. [4 with results of recent shock-tube measurements [7] for $\mathrm{CO} / \mathrm{H}_{2}$-air mixtures with $\phi=0.5$ and different $\mathrm{CO} / \mathrm{H}_{2}$ ratios representative of typical syngas mixtures. The conditions considered include near-atmospheric and elevated pressure, although no experimental measurements are available at

high pressure for the two mixtures with larger $\mathrm{H}_{2} / \mathrm{CO}$ ratio. As can be seen, the agreement found between the computations and the experiments is reasonably good for conditions that place the system above, around or slightly below crossover, such that the resulting induction times are small. For these lean mixtures, the previously discussed correction factor $\Lambda$ in essential for achieving accurate results; without this branching-rate correction, the reduced chemistry would predict the induction time to be less than one third of that obtained with detailed chemistry. The reduced-chemistry predictions are in excellent agreement with detailed-chemistry predictions until temperatures decrease below about $900 \mathrm{~K}$, where the need for further study of both computational and experimental results has been discussed widely in the literature [12, 13, 14].

\section{Concluding remarks}

The mechanism presented here can be used over a wide range of combustion conditions that include, in particular, most of those of gas-turbine operation. Calculations have indicated that its use decreases computation 
times by a factor, exceeding two, that may be as large as five depending on the specific test case. In view of the previously identified discrepancies between predictions of current chemical-kinetic mechanisms and experimental measurements [4, 5], further improvements of the reduced mechanism may stem from modifications in reaction rates of elementary steps, to be sought in future chemical-kinetic investigations, leading to better predictions of burning rates for strongly preheated mixtures as well as of induction times at temperatures below crossover. Further simplifications of the reduced description, arising for instance in connection with steady states of additional intermediaries, are worth pursuing in the future for application under more restrictive combustion conditions. For instance, a $\mathrm{HO}_{2}$ steady state is accurate within the main reaction layer in deflagrations, thereby leading to a three-step mechanism, which would, however, not be very accurate for describing autoignition. An even simpler description for syngas flames arises for conditions such that the peak temperature lies close to the crossover value, as occurs in very lean (or very rich) mixtures or in highly diluted environments, for which a two-step mechanism can be envisioned to be sufficiently accurate, with both $\mathrm{H}$ and $\mathrm{HO}_{2}$ maintaining steady state, as occurs in $\mathrm{H}_{2}$-air flames near the lean limit [15, 16].

\section{Acknowledgements}

This work was supported by the UE Marie Curie ITN MYPLANET, by the Comunidad de Madrid through project \# S2009/ENE-1597, and by the Spanish MCINN through projects \# ENE2008-06515 and CSD2010-00011.

\section{References}

[1] S. G. Davis, A. V. Joshi, H. Wang, and F. Egolfopoulos, Proc. Combust. Inst. 30 (2005) 1283-1292. 
[2] P. Saxena, F.A. Williams, Combust. Flame 145 (2006) 316-323. Also available at http://maeweb.ucsd.edu/ combustion/cermech/.

[3] H. Sun, S. I. Yang, G. Jomaas, C. K. Law, Proc. Combust. Inst. 31 (2007) 439-446.

[4] E. L. Petersen, D. M. Kalitan, A. B. Barret, S. C. Reehal, J. D. Mertens, D. J. Beerer, R. L. Hack, V. G. McDonell, Combust. Flame 149 (2007) 244-247.

[5] J. Natarajan, T. Lieuwen, J. Seitzman, Combust. Flame 151 (2007) 104-119.

[6] P. Boivin, C. Jiménez, A. L. Sánchez, F.A. Williams, Proc. Combust. Inst. 33 (2010) doi:10.1016/j.proci.2010.05.002.

[7] D. M. Kalitan, J. D. Mertens, M. W. Crofton, E. L. Petersen, J. Prop. Power 23 (2007) 1291-1303.

[8] Cosilab Collection, Rotexo-Softpredict-Cosilab GmbH \& Co. KG, Bad Zwischenahn (Germany), www.SoftPredict.com (2007).

[9] I. C. McLean, D. B. Smith, S. C. Taylor, Proc. Combust. Inst. 25 (1994) 749-757.

[10] C. Dong, Q. Zhou, Q. Zhao, Y. Zhang, T. Xu, S. Hui, Fuel 88 (2009) 1858-1863.

[11] J. Natarajan, Y. Kochar, T. Lieuwen, J. Seitzman, Proc. Combust. Inst. 32 (2009) 1261-1268.

[12] M. Chaos, F. L. Dryer, Combust. Sci. Tech. 180 (2008) 1053-1096. 
[13] S. P. Medvedev, G. L. Agafonov, S. V. Khomik, B. E. Gelfand, Combust. Flame 157 (2010) 1436-1438.

[14] D. E. Cavaliere, M. de Joannon, P. Sabia, Mi Sirignano, A. D’Anna, Combust. Sci. Tech. 182 (2010) 692-701.

[15] D. Fernández-Galisteo, A.L. Sánchez, A. Liñán, F. A. Williams, Combust. Flame 156 (2009) 985-996.

[16] D. Fernández-Galisteo, A.L. Sánchez, A. Liñán, F. A. Williams, Combust. Th. Modelling 13 (2009) 741-761. 


\begin{tabular}{|c|c|c|c|c|c|c|c|c|c|}
\hline & Reaction & & $A^{\mathrm{a}}$ & $n$ & $E^{\mathrm{a}}$ & & $A^{\mathrm{a}}$ & $n$ & $E^{\mathrm{a}}$ \\
\hline 1 & $\mathrm{H}+\mathrm{O}_{2} \rightleftharpoons \mathrm{OH}+\mathrm{O}$ & $k_{f}$ & $3.5210^{16}$ & -0.7 & 71.42 & $k_{b}$ & $7.0410^{13}$ & -0.26 & 0.60 \\
\hline 2 & $\mathrm{H}_{2}+\mathrm{O} \rightleftharpoons \mathrm{OH}+\mathrm{H}$ & $k_{f}$ & $5.0610^{4}$ & 2.67 & 26.32 & $k_{b}$ & $3.0310^{4}$ & 2.63 & 20.23 \\
\hline 3 & $\mathrm{H}_{2}+\mathrm{OH} \rightleftharpoons \mathrm{H}_{2} \mathrm{O}+\mathrm{H}$ & $k_{f}$ & $1.1710^{9}$ & 1.3 & 15.21 & $k_{b}$ & $1.2810^{10}$ & 1.19 & 78.25 \\
\hline 4 & $\mathrm{H}+\mathrm{O}_{2}+\mathrm{M} \rightarrow \mathrm{HO}_{2}+\mathrm{M}^{\mathrm{b}}$ & $k_{0}$ & $5.7510^{19}$ & -1.4 & 0.0 & $k_{\infty}$ & $4.6510^{12}$ & 0.44 & 0.0 \\
\hline 5 & $\mathrm{HO}_{2}+\mathrm{H} \rightarrow 2 \mathrm{OH}$ & & $7.0810^{13}$ & 0.0 & 1.23 & & & & \\
\hline 6 & $\mathrm{HO}_{2}+\mathrm{H} \rightleftharpoons \mathrm{H}_{2}+\mathrm{O}_{2}$ & $k_{f}$ & $1.6610^{13}$ & 0.0 & 3.44 & $k_{b}$ & $2.6910^{12}$ & 0.36 & 231.86 \\
\hline 7 & $\mathrm{HO}_{2}+\mathrm{OH} \rightarrow \mathrm{H}_{2} \mathrm{O}+\mathrm{O}_{2}$ & & $2.8910^{13}$ & 0.0 & -2.08 & & & & \\
\hline 8 & $\mathrm{H}+\mathrm{OH}+\mathrm{M} \rightleftharpoons \mathrm{H}_{2} \mathrm{O}+\mathrm{M}^{\mathrm{c}}$ & $k_{f}$ & $4.0010^{22}$ & -2.0 & 0.0 & $k_{b}$ & $1.0310^{23}$ & -1.75 & 496.14 \\
\hline 9 & $2 \mathrm{H}+\mathrm{M} \rightleftharpoons \mathrm{H}_{2}+\mathrm{M}^{\mathrm{d}}$ & $k_{f}$ & $1.3010^{18}$ & -1.0 & 0.0 & $k_{b}$ & $3.0410^{17}$ & -0.65 & 433.09 \\
\hline 10 & $2 \mathrm{HO}_{2} \rightarrow \mathrm{H}_{2} \mathrm{O}_{2}+\mathrm{O}_{2}$ & & $3.0210^{12}$ & 0.0 & 5.8 & & & & \\
\hline 11 & $\mathrm{HO}_{2}+\mathrm{H}_{2} \rightarrow \mathrm{H}_{2} \mathrm{O}_{2}+\mathrm{H}$ & & $1.6210^{11}$ & 0.61 & 100.14 & & & & \\
\hline 12 & $\mathrm{H}_{2} \mathrm{O}_{2}+\mathrm{M} \rightarrow 2 \mathrm{OH}+\mathrm{M}^{\mathrm{e}}$ & $k_{0}$ & $8.1510^{23}$ & -1.9 & 207.62 & $k_{\infty}$ & $2.6210^{19}$ & -1.39 & 214.74 \\
\hline 13 & $\mathrm{CO}+\mathrm{OH} \rightleftharpoons \mathrm{CO}_{2}+\mathrm{H}$ & $k_{f}$ & $4.410^{6}$ & 1.5 & -3.1 & $k_{b}$ & $2.4110^{13}$ & 0.22 & 104.60 \\
\hline 14 & $\mathrm{CO}+\mathrm{HO}_{2} \rightarrow \mathrm{CO}_{2}+\mathrm{OH}$ & & $6.0310^{13}$ & 0.0 & 96.0 & & & & \\
\hline 15 & $\mathrm{HCO}+\mathrm{M} \rightleftharpoons \mathrm{CO}+\mathrm{H}+\mathrm{M}^{\mathrm{f}}$ & $k_{f}$ & $1.8610^{17}$ & -1 & 71.13 & $k_{b}$ & $3.5110^{16}$ & -0.77 & 5.35 \\
\hline 16 & $\mathrm{HCO}+\mathrm{H} \rightarrow \mathrm{CO}+\mathrm{H}_{2}$ & & $5.010^{13}$ & 0.0 & 0.0 & & & & \\
\hline
\end{tabular}

Table 1: Rate coefficients in Arrhenius form $k=A T^{n} \exp \left(-E / R^{o} T\right)$ for the skeletal mechanism.

${ }^{a}$ Units are $\mathrm{mol}, \mathrm{s}, \mathrm{cm}^{3}, \mathrm{~kJ}$, and $\mathrm{K}$.

${ }^{b}$ Chaperon efficiencies are 2.5 for $\mathrm{H}_{2}, 16.0$ for $\mathrm{H}_{2} \mathrm{O}, 1.2$ for $\mathrm{CO}, 2.4$ for $\mathrm{CO}_{2}, 0.7$ for $\mathrm{Ar}$ and $\mathrm{He}$ and 1.0 for all other species; Troe falloff with $F_{c}=0.5$

${ }^{c}$ Chaperon efficiencies are 2.5 for $\mathrm{H}_{2}, 12.0$ for $\mathrm{H}_{2} \mathrm{O}, 1.9$ for $\mathrm{CO}, 3.8$ for $\mathrm{CO}_{2}, 0.5$ for $\mathrm{Ar}$ and $\mathrm{He}$ and 1.0 for all other species.

${ }^{d}$ Chaperon efficiencies are 2.5 for $\mathrm{H}_{2}, 12.0$ for $\mathrm{H}_{2} \mathrm{O}, 1.9$ for $\mathrm{CO}, 3.8$ for $\mathrm{CO}_{2}, 0.38$ for $\mathrm{Ar}$ and $\mathrm{He}$ and 1.0 for all other species.

${ }^{e}$ Chaperon efficiencies are 2.0 for $\mathrm{H}_{2}, 6.0$ for $\mathrm{H}_{2} \mathrm{O}, 1.5$ for $\mathrm{CO}, 2.0$ for $\mathrm{CO}_{2}, 0.4$ for $\mathrm{Ar}$ and He and 1.0 for all other species; $F_{c}=0.265 \exp (-T / 94 \mathrm{~K})+0.735 \exp (-T / 1756 \mathrm{~K})+$ $\exp (-5182 \mathrm{~K} / T)$

${ }^{f}$ Chaperon efficiencies are 1.9 for $\mathrm{H}_{2}, 12.0$ for $\mathrm{H}_{2} \mathrm{O}, 2.5$ for $\mathrm{CO}, 2.5$ for $\mathrm{CO}_{2}$ and 1.0 for all other species. 


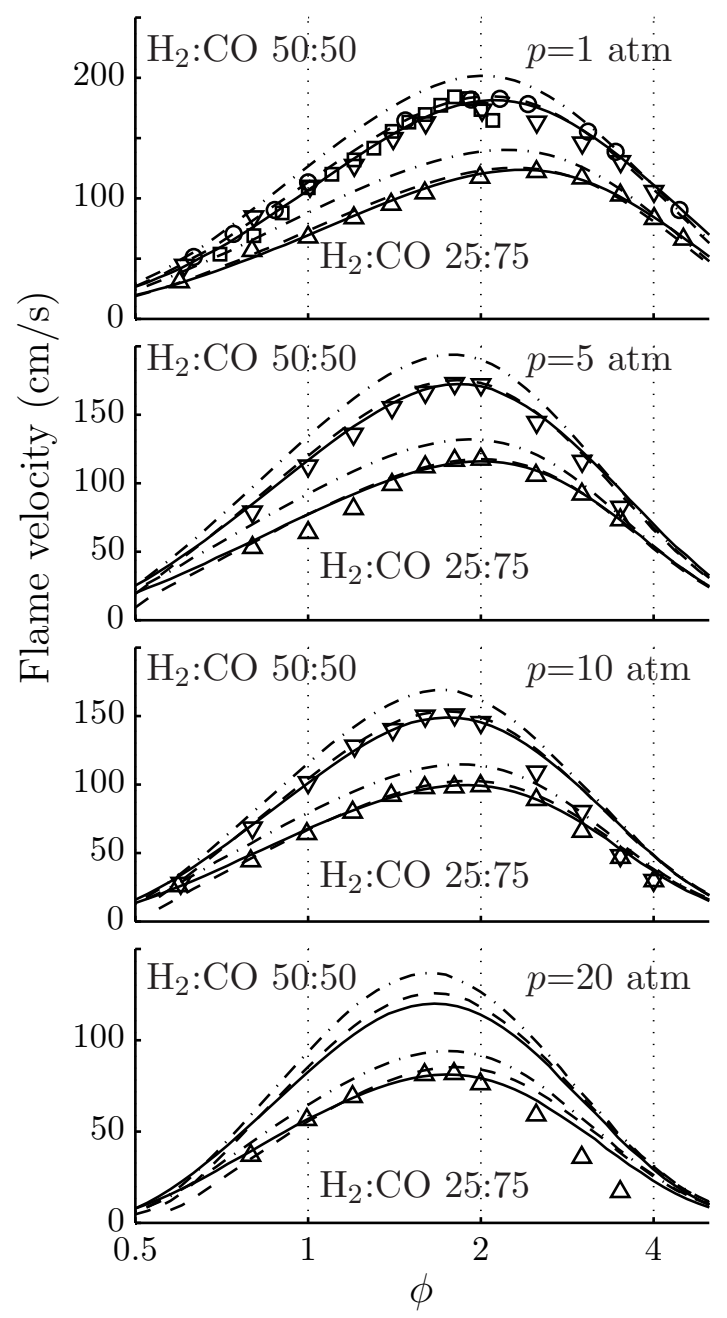

Figure 1: The variation with equivalence ratio of the laminar flame velocity for a $\mathrm{CO} / \mathrm{H}_{2}$-oxidizer mixture at initial temperature $T_{u}=300 \mathrm{~K}$ and for four different pressures and two different $\mathrm{CO} / \mathrm{H}_{2}$ ratios as obtained from numerical integrations with detailed (solid curves), skeletal (dashed curves), and reduced (dot-dashed curves) chemistry descriptions and from laboratory measurements (triangles: [3]; circles: [9]; squares: [10]); the oxidizer for $p=1$ atm is air, while for $p=(5,10,20)$ atm it is an oxygen-helium mixture with mole-fraction ratio $X_{\mathrm{He}} / X_{\mathrm{O}_{2}}=7[3]$. 


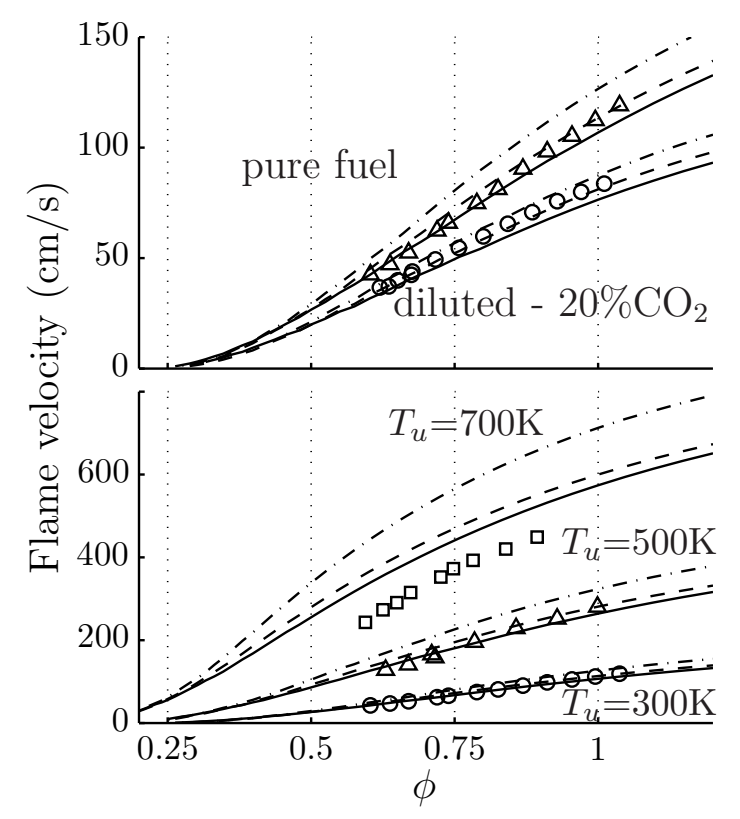

Figure 2: The variation with equivalence ratio of the laminar flame velocity for a $\mathrm{CO} / \mathrm{H}_{2} / \mathrm{CO}_{2}$-air mixture with $X_{\mathrm{CO}} / X_{\mathrm{H}_{2}}=1$ at $p=1$ atm as obtained from numerical integrations with detailed (solid curves), skeletal (dashed curves), and reduced (dot-dashed curves) chemistry descriptions and from laboratory measurements (symbols: [5]). The lower plot shows results for $X_{\mathrm{CO}_{2}}=0$ with three different values of $T_{u}$ while the upper plot shows results for $T_{u}=300 \mathrm{~K}$ with $X_{\mathrm{CO}_{2}}=0$ and with $X_{\mathrm{CO}_{2}}=0.2$ in the fuel mixture. 


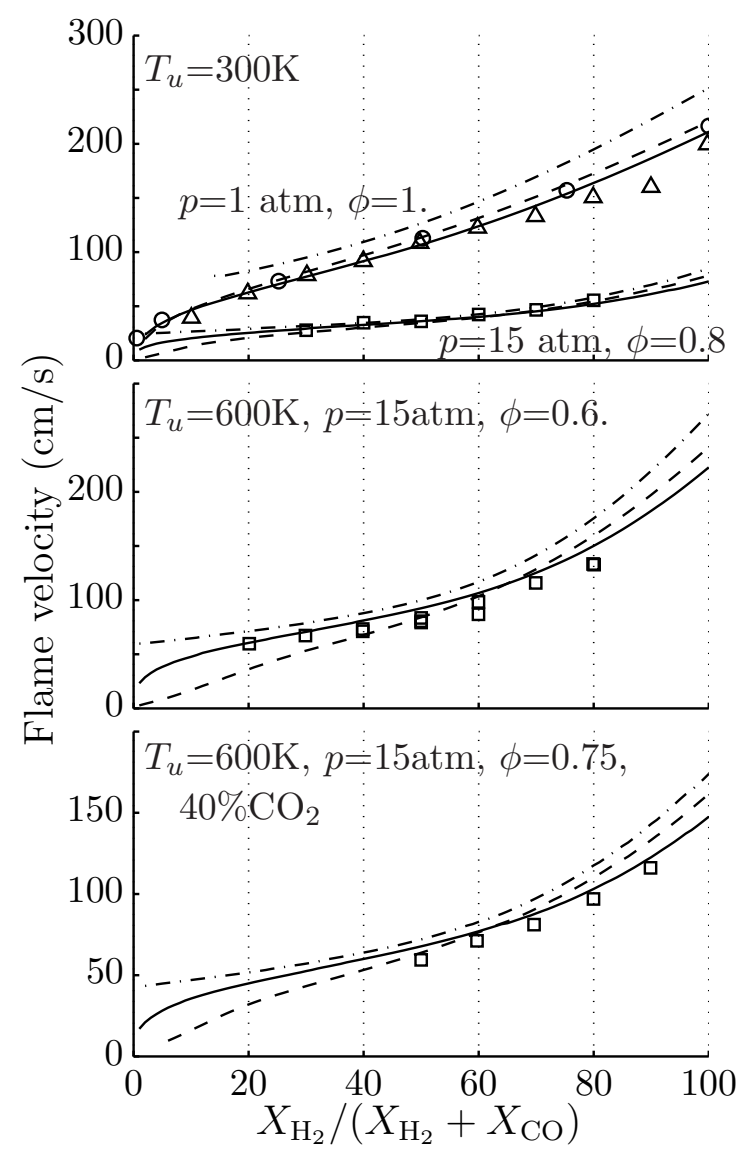

Figure 3: The variation of the laminar flame velocity with the fuel composition for a $\mathrm{CO} / \mathrm{H}_{2} / \mathrm{CO}_{2}$-oxidizer mixture as obtained from numerical integrations with detailed (solid curves), skeletal (dashed curves), and reduced (dot-dashed curves) chemistry descriptions and from laboratory measurements (circles: [9]; triangles: [10]; squares: [11]). The oxidizer is air for $p=1$ atm and a helium-oxygen mixture with mole-fraction ratio $X_{\mathrm{He}} / X_{\mathrm{O}_{2}}=9$ for $p=15$ atm. Fuel dilution with $\mathrm{CO}_{2}$ is considered in the bottom plot; all other cases correspond to undiluted $\mathrm{CO} / \mathrm{H}_{2}$ fuel mixtures. 


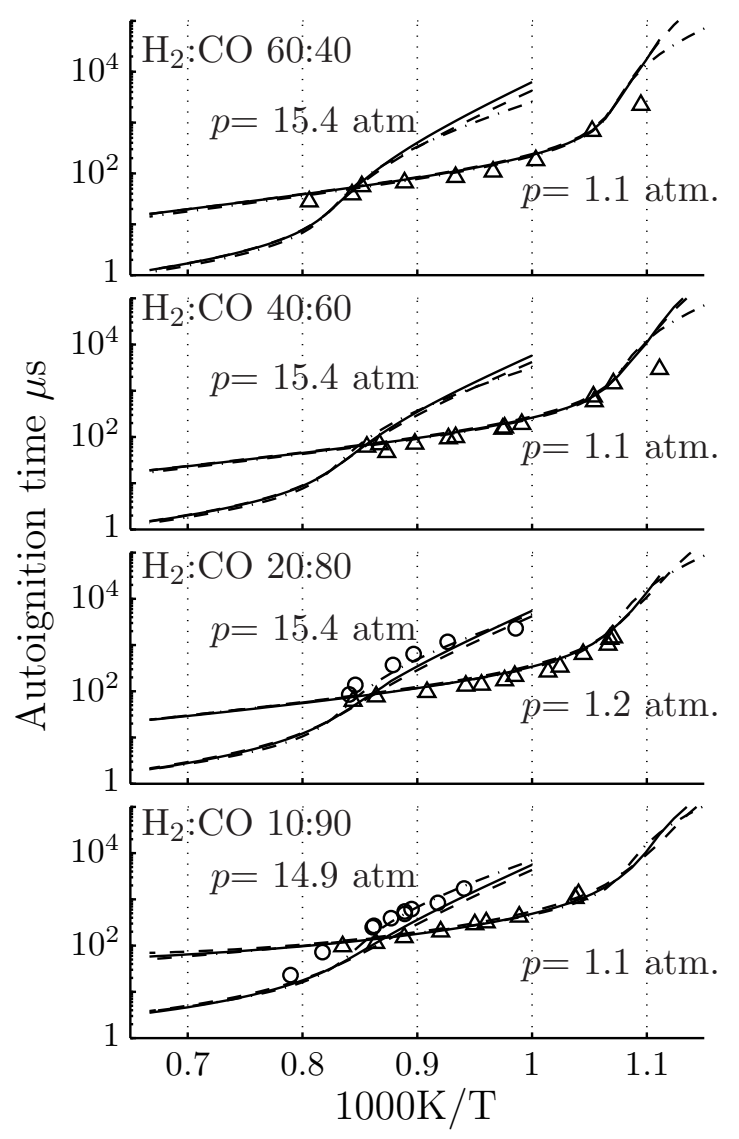

Figure 4: The variation with initial temperature of the induction time for a $\mathrm{CO} / \mathrm{H}_{2}$-air mixture with $\phi=0.5$ as obtained from numerical integrations with detailed (solid curves), skeletal (dashed curves), and reduced (dotdashed curves) chemistry descriptions and from laboratory measurements (symbols: [7]). 